\title{
Daily crime flows within a city
}

\author{
Marcus Felson ${ }^{1 *}$ and Rémi Boivin ${ }^{2}$
}

\begin{abstract}
Objectives: This paper uses transportation data to estimate how daily spatio-temporal shifts in population influence the distribution of crime over a city's census tracts (CTs). A "funnel hypothesis" states that these daily flows are central for crime concentrations within a city. We present arguments for and against funneling prior to empirical analysis.

Methods: A municipal transport agency in a large city in Eastern Canada surveyed 66,100 households about daily trips for work, shopping, recreation, and school. This allowed us to link inflows of visitors to numbers of property and violent crimes for 506 CTs.
\end{abstract}

Results: We find strong support for a funneling effect. Daily visitors have a major impact on distributions over this city for both violent and property crimes.

Conclusions: Daily spatio-temporal shifts could be significantly more important than fixed residential factors for distributing crime over urban space.

Keywords: Ambient population, Routine activities, Census tracts, Crime geography, Spatio-temporal analysis, Distance to crime

\section{Background}

Ninety years ago, Burgess (1925) noted that people often commit crimes in census tracts (CTs) where they do not reside. That early finding is relevant to a contemporary research question-why does urban crime concentrate in some places? Such concentrations have long been associated with social features of the residential population, but it is increasingly evident that daily nonresidential activities distribute crime unevenly over space, beyond residential effects.

\section{Crime's spatial concentration, without a temporal dimension}

Clarke and Eck (2005) have stated a larger rule of concentration, the 80-20 rule, which tells us that crime is highly concentrated among offenders, victims, or places. In particular, the highly unequal distribution of crime over urban space has been well documented. Approximately $5 \%$ of street segments produce at least half the crime in several cities (Weisburd et al. 2012). Crime concentration tendencies have been shown strongly in Britain (Johnson

\footnotetext{
*Correspondence: mf38@txstate.edu

1 School of Criminal Justice, Texas State University, San Marcos, TX, USA Full list of author information is available at the end of the article
}

2010, 2014), Australia (Townsley et al. 2014), and the Netherlands (Bernasco and Luykx 2003). In addition, Andresen and Malleson (2013) observed crime concentrations at three spatial scales in the same city: street segments, CTs, and dissemination areas.

\section{Land use studies, implying a temporal dimension}

Several studies have linked crime to variations in land use. Shaw and McKay (1942) and White (1932) included local land use variables in their analyses. The Brantinghams $(1975,1981)$ considered how certain local land uses set the stage for proximate crimes. Dennis Roncek related block-level crime to such land uses as secondary schools and bars (see Roncek and Bell 1981; Roncek and Lobosco 1983; Roncek and Fagianni 1985; Roncek and Maier 1991). An array of subsequent studies linked crime spatially to liquor establishments and other risky facilities (Bowers 2013; Franquez et al. 2013; Groff 2011; Romley et al. 2007; Zhu et al. 2004; Groff and Lockwood 2014; Roman and Reid 2012).

As several scholars have already recognized, these land use studies have a temporal dimension by implication (McCord and Ratcliffe 2009; Tompson and Townsley 2010). A barroom brings out people at night, while a

\section{Springer}


school enhances daytime population. A workplace shifts population according to work schedule. Moreover, every type of land use producing inflows for one place also causes outflows from another location.

Land use is even more clearly related to crime when disaggregating by season (Andresen and Malleson 2013). For example, crime concentrates in summer near major parks and beaches, but elsewhere in other seasons when visitor patterns differ. Indeed, the relationship between land use and crime should be thought of in spatio-temporal terms. Despite all we have learned from land use analyses, more direct measures of daily population flows are desirable, but difficult to find. The current research will not be able to provide the ideal data for such purposes, but we will be able to offer an intermediate approach, using transportation surveys to measure daily activity flows, and then relate these flows to crime. Some existing theoretical ideas on spatio-temporal crime patterns prove useful for this analysis.

\section{The "Funneling Hypothesis"}

Patricia and Paul Brantingham (1975, 1981, 1995, 1999) established several principles for studying offender movements in urban space:

1. In daily life, offenders move around rather like nonoffenders.

2. Each offender's daily awareness space is defined by routine activity locations-home, workplace, school, shopping, and recreation-as well as by the routes linking these locations.

3. Offenders commit crimes within their awareness spaces, or near-by.

4. Extra crime occurs where larger numbers of people visit. $^{1}$

These basic principles tell us that an urban system could well shift crime risk unequally in space and time. We might view a city as a set of funnels, moving people into some areas and out of others on a daily basis. In the course of these movements, some people become crime participants outside their zone of residence (as Burgess had suggested in 1925). This "funneling hypothesis" implies that an appreciable share of crime within a CT might be generated by non-residents visiting on a frequent basis.

\footnotetext{
${ }^{1}$ Our analysis neglects some important dimensions of the Brantinghams' work, such as (a) their distinction between crime attractors and crime generators, (b) their focus on edges of neighborhoods, and (c) their emphasis on street patterns. These ideas are implicit but not explicit in the current paper. We also translate their concept of "insiders vs. outsiders" to "residents vs. visitors" for purposes of this presentation.
}

Groff and McEwen (2007) confirmed the Burgess point that many crimes occur at noteworthy distances from the home of offender and/or victim (see also Bernasco 2010; Bernasco and Block 2011; Rossmo et al. 2012; Townsley and Sidebottom 2010; Andresen et al. 2014; Johnson 2014; Pyle 1974; Hakim and Rengert 1981). Moreover, Frank et al. (2013) showed that offenders tend to go in certain directions, such as towards malls or entertainment zones. The directionality point is also highly relevant to crime concentrations on public transport (Newton 2008). In a logical sense, offender directionality further implies that an urban system funnels potential crime participants into some places and away from others. Although that conclusion seems to be non-controversial, there are reasons to question it and to verify whether and when it fits the data.

\section{Arguments against the funneling hypothesis}

Despite the strong arguments for a funneling process, there are at least four logical reasons to doubt the hypothesis:

1. Population movements within a city could cancel each other out, with CTs losing and gaining similar numbers of offenders or targets.

2. Residential effects could easily swamp visitor effects, given that residents tend to spend much more time in their home CT than do most visitors.

3. After leaving their home CT, residents could easily spread crime risk along their entire route, diluting any visitor effects at their destination $\mathrm{CT}$.

4. In departing from their home $\mathrm{CT}$, residents reduce local guardianship, perhaps increasing crime near home as much as they supplement crime elsewhere.

These doubts are mitigated by some preliminary evidence supporting a funneling process. Stults and Halbrouk (2015) compared crime rates for 166 American cities with over 100,000 inhabitants showing that commuters can have a major impact on rates. For example, taking account of commuters dropped Washington, D.C., from 14th to 23rd in its homicide rate. Localized analyses of population flows further justify the funneling argument. Andresen (2010) calculated that some Vancouver suburbs double their daily population, while others lose half of their population due to daily routines; these plusses and minuses affect crime risks. For the city of Ottawa, Larue and Andresen (2015) linked vehicle theft and burglary risks to inflows of 65,000 university students, instructors and staff for two large universities. Also consistent with the funneling hypothesis, Boivin (2013) documented high levels of visitor participation in burglary and non-domestic assaults. 


\section{Past measurement efforts}

One half century ago, Boggs (1965) imagined a daily population census that could tell us how many people flow in urban space-time. Boggs used proxy measures, such as the area of sidewalks to estimate pedestrian inflows. Her goal was to find better denominators for measuring crime rates, a goal revisited by others (Harries 1991; Clarke 1984; Ratcliffe 2010; Cohen and Felson 1979; Stults and Halbrouk 2015).

Cohen and Felson (1979) estimated crime rates per billion person hours spent among strangers. The results were dramatic, but the categories were rather crude given the time use data available at the time. More recently, The American Time Use Survey made it possible to calculate national violent victimization rates with time denominators with more disaggregation (Lemieux 2010; Lemieux and Felson 2012). However, none of these publications were able to localize the impact of shifting population on crime concentration processes. More recent work by Stults and Halbrouk 2015) carried the spatio-temporal analysis one step farther. Their work showed that crime rates change greatly when commuter inflows are considered in the denominator of a city's crime rate. However, they were unable to study within-city variations due to Census Bureau privacy limitations on releasing commuter data for small areal units.

The ideal study would contain all the blocks in a city, and would measure crime distributions and population flow details for all blocks. A city with 10,000 blocks would probably require interviewing at least 200,000 persons (20 per block) to obtain a reasonable map of population flows within a city. Given the prohibitive cost of such a study, we can understand why the studies cited earlier used land use indicators to classify blocks rather than attempting to measure population flows more directly. The current paper takes a different approach. Having found a very large transit survey, we worked at the census tract level. With approximately $500 \mathrm{CTs}$ and 60,000 respondents, a mean of 120 respondents were found per spatial unit. Before proceeding to the data, their functional form is a matter for further discussion.

\section{What form should the funneling function take?}

Although offenders and targets tend to increase crime risk as they converge, guardians might play the opposite role. ${ }^{2}$ Angel (1968) presented a curvilinear model of street robbery risk, stating that robbery is least likely at the lowest and highest levels. At the lowest levels too few targets are around for robbers to attack, while the highest

\footnotetext{
${ }^{2}$ For more on guardianship, see Reynald $(2009,2011)$ and Hollis-Peel et al. (2012).
}

street density levels bring sufficient guardians to make an attack more difficult. Although Clarke et al. (2007) did not support the hypothesis within the New York City subway stations, it remains plausible to argue that an influx of visitors includes offenders, Kurland et al. (2014) learned that the timing of crimes near and within football stadiums near kickoff time reflects some of Angel's thinking.

In studying the impact of visitors on CT crime levels, we can imagine a mathematical function with more visitors producing more crimes up to a point, after which visitors create sufficient guardianship to produce something of a downward turn. Such a "concave-downward quadratic function" might describe how numbers of visitors and numbers of crimes relate over CTs. Alternatively, more visitors could lead to an upward curve in crime risk. Perhaps crowds of rowdy drinkers multiply violence risk, or very large numbers of parked cars have a disproportionate effect on vehicle theft by blocking the ability to see what offenders are doing. If so, the slope could take the form of a "concave-upward quadratic function." However, it is also possible that a simple straight line can relate visitor flows to crime concentrations. First we inquire whether there is a relationship, and then we seek to measure its form.

\section{Current data}

Transportation surveys are a longstanding tool for urban planning, not normally applied to crime analysis. Unfortunately, transportation surveys seldom have large enough samples to study each CT within a city. We were fortunate to gain partial access to an exceptionally large local transportation survey for a major city in Eastern Canada and were able to link it to crime risks. The survey includes multiple transportation modes and produces counts of daily population inflows into each of $506 \mathrm{CTs}$, both from other CTs and from the suburban ring around the city. However, we are unable to measure tourist inflows or long-distance commuters from beyond the regular commuting zone. $^{3}$

The current crime analysis is limited to within-city offenses, excluding crime occurring in the surrounding suburbs. The suburban exclusion limits the socioeconomic range of analysis. Accordingly, this study does not specifically seek to address social disorganization theory. Instead, we focus solely on determining the viability of the funneling hypothesis as a supplementary approach. Our three data sources include:

\footnotetext{
${ }^{3}$ Some have studied crime in or near transportation systems themselves. See Uittenbogaard (2013).
} 
(a) A 2008 transportation survey of 66,100 households, including questions about locations where respondents work and shop, or engage in recreation and education. The survey allowed us to estimate daily population flows into each CT for those four purposes.

(b) Police data on reported violent and property crimes by CT, made available for 2011 .

(c) Social data for CT residents from the 2006 Census.

Before proceeding, we note certain limitations of these data. We were unable to disaggregate educational trips by age or grade level. Thus educational flows include elementary school ages, not as likely to be crime participants. The social data were taken from the 2006 Census because the later census (2011) shifted policies and measurement procedures. The 2006 Census provides the percent of census tract households with low income before tax cut-offs, ${ }^{4}$ the percent of census tract families that are single-headed, and the percent of census tract population who moved within the last 5 years.

\section{Data analysis}

Distributions of key variables over the city are examined in two ways. First, we examine whether a relatively small share of CTs concentrate either crimes or their correlates. Later, we use more conventional statistics to relate visitor inflows to crime levels.

\section{Visitor concentrations}

Table 1 examines the concentrations of five key variables, taken one at a time. Only $6 \%$ of CTs concentrate $25 \%$ of the property crimes. Only $9.5 \%$ of CTs concentrate $25 \%$ of violent crimes. About one-fourth of CTs concentrate about one half of crimes of both types (right column). Although these crime concentrations are not as extreme as found in studies based on block data, a considerable degree of inequality is found. ${ }^{5}$

Even more interesting is the concentration of non-residents visiting CTs during their daily routines. A mere $1 \%$ of CTs account for one-fourth of all work visitors; $7 \%$ of

\footnotetext{
${ }^{4}$ Low income is defined as income levels at which families or persons not in economic families spend $20 \%$ more than average of their before tax income on food, shelter and clothing.

5 An anonymous reviewer noted that "[ $\mathrm{t}$ ]hese concentrations are not as extreme as block level data, but this is to be expected because block data have a lot of zero values, almost by definition: 1000 criminal events on 10,000 street segments, for example, has a minimum concentration of $10 \%$." While we do have low values, none of the CTs has a value of zero for either measures of crime or population (lowest $=23$ crimes in one CT). In fact, 114,872 crimes are spread over 506 CTs, for a minimal concentration (or average) of approximately 227 crimes. Furthermore, the coefficient of variation of 0.96 shows that the dataset has considerable variability. In that sense, the concentrations we found for this city are rather high.
}

Table 1 Crime and visitor concentrations, 25 and $50 \%$ levels, Eastern Canadian city

\begin{tabular}{|c|c|c|c|}
\hline \multicolumn{2}{|c|}{ Variables based on counts } & \multicolumn{2}{|c|}{$\begin{array}{l}\text { Percent of census tracts } \\
\text { containing }\end{array}$} \\
\hline & Shares of: & $\begin{array}{l}25 \% \text { of the } \\
\text { "shares" }\end{array}$ & $\begin{array}{l}50 \% \text { of the } \\
\text { "shares" }\end{array}$ \\
\hline \multirow{2}{*}{$\begin{array}{l}\text { Reported crimes, } \\
2011\end{array}$} & Property crimes & 6.3 & 23.1 \\
\hline & Violent crimes & 9.5 & 25.7 \\
\hline \multirow[t]{4}{*}{ Visitors, 2008} & For work & 1.0 & 6.9 \\
\hline & For shopping & 2.0 & 8.9 \\
\hline & For recreation & 4.7 & 17.0 \\
\hline & For education & 2.2 & 9.7 \\
\hline
\end{tabular}

Base $\mathrm{N}=506$ census tracts

CTs monopolize one-half of work visitors. Two percent of CTs account for a quarter of shoppers and $9 \%$ of CTs account for half of all shoppers. Recreation and education visitors also show noteworthy concentrations. This tells us that visitor concentrations are strong enough to influence crime concentrations, but the task remains to demonstrate the magnitude of influence.

\section{Linking visitors concentrations to crimes concentrations}

Table 2 looks at concentration in a different way. For each of the four activity variables, we separate the top $5 \%$ of CTs in numbers of visitors $(n=25)$. We then calculate the share of crimes committed in these CTs with the most visitors of each type. Those $5 \%$ of CTs with the most work visitors account for $16.2 \%$ of the property crime, over three times what would be expected if work concentration were unrelated to crime concentration. CTs with the most workers and shoppers tend to have three times their share of property crimes and twice their share of violent crimes. Recreation effects are even stronger, but education visitors have a smaller impact on crime concentration.

Similar thinking is applied in Table 3 to the top $25 \%$ of CTs $(n=125)$ for visitors of each type. These CTs have more than their share of crime, but the excesses are not dramatic. The weakest relationship is for education visitors, with the

Table 2 Share of crimes for top $5 \%$ of census tracts, Eastern Canadian city

\begin{tabular}{lll}
\hline $\begin{array}{l}\text { Top } \mathbf{5} \% \text { of CTs for each } \\
\text { type of visitor, 2008 } \mathbf{N}=\mathbf{2 5})\end{array}$ & $\begin{array}{l}\text { Share of property } \\
\text { crimes, 2011 (\%) }\end{array}$ & $\begin{array}{l}\text { Share of violent } \\
\text { crimes, 2011 (\%) }\end{array}$ \\
\hline For work & 16.2 & 10.7 \\
For shopping & 15.6 & 10.2 \\
For recreation & 18.7 & 12.2 \\
For education & 11.2 & 8.6 \\
\hline
\end{tabular}

Base $\mathrm{N}=506$ census tracts 
Table 3 Share of crimes for top $\mathbf{2 5} \%$ of census tracts, Eastern Canadian city

\begin{tabular}{lll}
\hline $\begin{array}{l}\text { Top 25 \% for each } \\
\text { type of visitor, 2008 } \\
(\mathbf{N}=\mathbf{1 2 6})\end{array}$ & $\begin{array}{l}\text { Share of property } \\
\text { crimes, 2011 (\%) }\end{array}$ & $\begin{array}{l}\text { Share of violent } \\
\text { crimes, 2011 (\%) }\end{array}$ \\
\hline For work & 46.7 & 37.6 \\
For shopping & 42.2 & 35.9 \\
For recreation & 45.8 & 37.3 \\
For education & 34.9 & 32.3 \\
\hline
\end{tabular}

Base $\mathrm{N}=506$ census tracts

top quarter of CTs producing a third of property and violent crimes. However, the top tier of CTs for work, schooling and recreation range contain from 42 to $47 \%$ of property crimes and 36 or $37 \%$ of violent crimes. The data so far show that the funneling hypothesis remains viable as a supplementary explanation of crime concentrations in this city.

\section{Further explorations of distributions}

The 2006 Census allowed us to examine how social features of the residential population distribute over CTs. These comparisons are not exactly parallel to visitor data, because social variables are reported as percentages of other units, as described earlier. However, Table 4 shows that social features of the residential population are much more evenly distributed than numbers of visitors. The coefficient of variation is presented in the last column, showing that residential components have low standard deviations relative to their means. Moreover, the means and medians are very close, indicating rather symmetrical distributions of residential social features over $506 \mathrm{CTs}$. In contrast, the number of visitors varies a great deal over CTs, with high coefficients of variation. For three of the four visitor indicators, the standard deviations are double or triple the size of the mean. The exception is for recreation, whose coefficient of variation is 1.3 , perhaps reflecting the possibility that recreational visits to family and friends do not flow into entertainment districts. For each visitor variable, there is quite a gap between mean and median, reflecting the lopsided concentrations of visitors for some CTs. To sum up, visitor flows over CTs are both disproportionate and skewed. The skewness of key variables is described in the following text table.

\begin{tabular}{lc}
\hline Variable & Skewness value \\
\hline Property crime & 6.08 \\
Violent crime & 2.05 \\
Work visitors & 12.37 \\
Shopping visitors & 6.45 \\
Recreation visitors & 5.03 \\
Education visitors & 6.13 \\
\hline
\end{tabular}

In contrast, social variables in this city are distributed over CTs within this city on a relatively more equal basis and with greater symmetry around the mean.

\section{Correlating crime with visitor components}

Next we correlate CT crime rates, visitor rates, and census social variables. For this analysis, all variables are calculated as a percent of residential population, except for low income (available only as a percent of households) and single parents (available only as a percent of families). Table 5 shows a striking contrast in magnitude of correlations. In the upper right hand section of the matrix, correlations between crime rates and three of the four visitor variables range from 0.72 to 0.95 . On the other hand, education inflows only correlate around 0.5 with property and violent crime rates, perhaps reflecting our inability to separate flows of high school youths

Table 4 Descriptive statistics for residents, visitors, and crimes, Eastern Canadian city

\begin{tabular}{|c|c|c|c|c|c|}
\hline \multirow[t]{2}{*}{ Variables } & & \multicolumn{4}{|c|}{ Descriptions for census tract data } \\
\hline & & Median & Mean & $\begin{array}{l}\text { Standard } \\
\text { deviation }\end{array}$ & $\begin{array}{l}\text { Coefficient } \\
\text { of variation }\end{array}$ \\
\hline \multirow[t]{3}{*}{ Residents, 2006} & $\%$ Households low income & 29.2 & 30.1 & 13.4 & 0.44 \\
\hline & $\%$ Families single parent & 20.8 & 21.1 & 7.4 & 0.35 \\
\hline & $\%$ Persons moved past 5 years & 44.2 & 44.8 & 10.9 & 0.24 \\
\hline \multirow[t]{4}{*}{ Visitors, 2008} & For work & 744.1 & 1928.4 & 5900.5 & 3.06 \\
\hline & For shopping & 255.2 & 598.6 & 1276.3 & 2.13 \\
\hline & For recreation & 376.4 & 555.5 & 720.1 & 1.30 \\
\hline & For education & 395.8 & 845.6 & 1681.5 & 1.99 \\
\hline \multirow[t]{2}{*}{ Number of reported crimes, 2011} & Violent crimes & 37.0 & 44.4 & 31.9 & 0.71 \\
\hline & Property crimes & 137.0 & 182.6 & 193.8 & 1.06 \\
\hline
\end{tabular}

Base $\mathrm{N}=506$ census tracts

a Coefficient of variation $=$ standard deviation $/$ mean 
Table 5 Pearson's r matrix for visitor, residential, and crime variables, Eastern Canadian city

\begin{tabular}{|c|c|c|c|c|c|c|c|c|}
\hline \multirow[t]{2}{*}{ Variables } & \multirow{2}{*}{$\begin{array}{l}2 \text { Property } \\
\text { crime }\end{array}$} & \multicolumn{3}{|c|}{ Residential variables } & \multicolumn{4}{|c|}{ Visitor variables } \\
\hline & & 3 Low income & $\begin{array}{l}4 \text { Single } \\
\text { parent }\end{array}$ & $\begin{array}{l}5 \text { Moved, } \\
5 \text { years }\end{array}$ & 6 For work & $\begin{array}{l}7 \text { For } \\
\text { shopping }\end{array}$ & $\begin{array}{l}8 \text { For } \\
\text { recreation }\end{array}$ & $\begin{array}{l}9 \text { For } \\
\text { education }\end{array}$ \\
\hline 1. Violent crime & 0.94 & 0.26 & -0.03 & 0.30 & 0.82 & 0.72 & 0.92 & 0.51 \\
\hline 2. Property crime & & 0.13 & -0.14 & 0.23 & 0.95 & 0.86 & 0.90 & 0.47 \\
\hline 3. Low income & & & 0.58 & 0.60 & 0.05 & 0.04 & 0.12 & 0.12 \\
\hline 4. Single parents & & & & 0.27 & -0.15 & -0.13 & -0.12 & -0.16 \\
\hline 5. Moved 5 years & & & & & 0.13 & 0.10 & 0.21 & 0.23 \\
\hline 6. For work & & & & & & 0.92 & 0.81 & 0.32 \\
\hline 7. For shopping & & & & & & & 0.68 & 0.26 \\
\hline 8. For recreation & & & & & & & & 0.46 \\
\hline 9. For education & & & & & & & & \\
\hline
\end{tabular}

Variable 3 reports percent of households low in income in 2006

Variable 4 reports percent of families single parent in 2006

All other variables calculated as a percentage of residential population in 2011

All statistics over 0.10 in absolute value are significant at the 0.01 level

Base $\mathrm{N}=506$ census tracts

from flows of younger children who are less problematical. In contrast, the correlations between residence-based social variables and crime rates range from near 0 to 0.3 . Table 5 is highly consistent with the funneling hypothesis, showing that it visitor variables have strong correlations with crime variables, and that visitor effects in this city exceed residential effects by a considerable margin.

Given the magnitude of the visitor-crime correlations, we conducted a sensitivity analysis (Table 6) with log and square root transformations. A strong correlation between visitors and crimes is consistently found. Opinion differs about whether or when to correlate ratio-level variables as opposed to counts (Chamlin and Cochran 2004), but the relationship remains strong in either case. For example, the correlations for work visitors and property crimes range from 0.69 to 0.95 , depending on variable form. Half of the correlations are 0.80 or greater, with 0.57 the lowest of the 12 correlations, all of which are highly significant statistically. The funneling hypothesis

Table 6 Sensitivity analysis of Pearson's r, between property crimes and visitors for work, shopping, and recreation, Eastern Canadian city

\begin{tabular}{llll}
\hline Both variables as & \multicolumn{2}{l}{$\begin{array}{l}\text { Correlation between property crimes } \\
\text { and visitors }\end{array}$} \\
\cline { 2 - 4 } & For work & For shopping & For recreation \\
\hline Counts & 0.85 & 0.66 & 0.80 \\
Square root of counts & 0.80 & 0.63 & 0.75 \\
Log of counts & 0.69 & 0.57 & 0.67 \\
$\begin{array}{l}\text { Ratios to residential } \\
\text { population }\end{array}$ & 0.95 & 0.86 & 0.90 \\
\hline
\end{tabular}

Base $\mathrm{N}=506$ census tracts clearly survives this sensitivity analysis. We next turn to the quadratic equations discussed earlier.

\section{Separate quadric equations for visitor flows and crimes}

Our next goal is to determine whether visitors and crime relate in a concave downward quadratic function, a concave-upward quadratic function, or simply a straight line. The general equation form is

$$
\mathrm{Y}=\mathrm{a}+\mathrm{bX}+\mathrm{c} \mathrm{X}^{2},
$$

where $\mathrm{Y}$ is the number of crimes and $\mathrm{X}$ is the number of visitors. Coefficient $c$ is most relevant for assessing the curvature of the line.

If the quadratic effect, c, is negative, the curve is concave-downward; if positive, the curve is concave upward; if coefficient $\mathrm{c}$ is non-significant, the relationship can then be described as a straight line. However, measuring a quadratic effect really requires a much larger sample than offered here, so we consider the results in Tables 7 and 8 as suggestive for its quadratic component.

Table 7 explores the equation for one visitor component at a time. Those visiting a CT for work, shopping, or education all have negative coefficients for the quadratic effect, hence concave-downward curves. This implies that the impact of visitors on crime begins with a good upward slope, but then begins to taper off as the number of visitors reaches higher levels. Note that the quadratic coefficient is multiplied by the number of visitors squared, so large crowds can at some point diminish crimes. The data clearly imply that more visitors make more crime as a general rule, with tapering when inflows reach high levels. That is consistent with the idea that 
Table 7 Quadratic equations relating crimes to visitors for work, shopping, recreation, and education, Eastern Canadian city

\begin{tabular}{|c|c|c|c|c|c|}
\hline \multirow[t]{2}{*}{ Visitor counts } & \multirow[t]{2}{*}{ Crime counts } & \multicolumn{4}{|c|}{ Equation form: $Y=a+b X+c X 2$} \\
\hline & & Constant a & Main effect $\left(10^{3}\right) b$ & Quadratic effect $\left(10^{6}\right) \mathrm{c}$ & Multiple R \\
\hline \multirow[t]{2}{*}{ For work } & Property & $107.3^{* *}$ & $42.9^{* *}$ & $-0.2^{* *}$ & 0.878 \\
\hline & Violent & $36.0^{* *}$ & $4.9^{* *}$ & $-0.03^{* *}$ & 0.547 \\
\hline \multirow[t]{2}{*}{ For shopping } & Property & $116.9^{* *}$ & $115.3^{* *}$ & -1.7 & 0.657 \\
\hline & Violent & $34.2^{* *}$ & $20.6^{* *}$ & $-1.0^{* *}$ & 0.470 \\
\hline \multirow[t]{2}{*}{ For recreation } & Property & $84.7^{* *}$ & $158.8^{* *}$ & $11.7^{* *}$ & 0.804 \\
\hline & Violent & $28.4^{* *}$ & $29.2^{* *}$ & -0.2 & 0.637 \\
\hline \multirow[t]{2}{*}{ For education } & Property & $136.2^{* *}$ & $68.3^{* *}$ & $-3.2^{* *}$ & 0.310 \\
\hline & Violent & $36.5^{* *}$ & $12.1^{* *}$ & $-0.6^{* *}$ & 0.311 \\
\hline
\end{tabular}

Base $\mathrm{N}=506$ census tracts

** Significant at 0.01 level

sufficient visitors provide guardianship, somewhat offsetting the main effects of additional offenders and targets. Yet that rule does not apply for recreation visitors, whose slope is concave-upward for property crimes and a simple straight line for violent crimes.

Given the small number of cases used to fit this quadratic curve, we cautiously note that for all eight equations, the $y$-intercepts (coefficient a) are positive and significant. If the number of visitors goes to zero, an average CT will still have crime-predicted to be from 87 to 117 property crimes and from 28 to 36 violent crimes as baseline risk levels, likely generated by residential populations. The same equations indicate that every thousand workers "bring" 43 property crimes and five violent crimes. At the other extreme, every thousand recreation visitors correspond to 156 property crimes and 29 violent crimes. Apparently, recreation visitors have the greatest relative impact on local crime. The work visitor equation for property crime has highest Multiple- $\mathrm{R}(0.878)$ of all eight equations. The recreation equation has the strongest main effects for violent and property crimes, alike. The multiple $\mathrm{R}$ for education visitors is much smaller than the others, probably reflecting the data limitations already discussed. We drop the education variable from our summary analysis due to measurement limitations.

\section{Summary equations relating CT crime counts to visitor flows}

We now place three flows of visitors together, as presented in Table 8. Again, our $\mathrm{N}$ is too small to take the quadratic coefficient within this equation as definitive. The Multiple R for property crimes now passes 0.9 , and that for violent crimes is 0.66 . The main effects all appear strong and significant. In the final property crime equation, every thousand workers visiting a CT produce a surprising 828 additional property crimes there over a 1 year
Table 8 Quadratic equation relating crimes to visitors for work, shopping, and recreation, Eastern Canadian city

\begin{tabular}{|c|c|c|c|}
\hline \multicolumn{4}{|c|}{$C=a+b W+c W^{2}+d Q+e Q^{2}+f Z+g Z^{2}$} \\
\hline & & Property crimes & Violent crimes \\
\hline Intercept & Constant: a & $74.3^{* *}$ & $27.5^{* *}$ \\
\hline \multirow[t]{2}{*}{$W=$ for work } & $\begin{array}{l}\text { Main effect: } \\
\qquad\left(10^{3}\right) \mathrm{b}\end{array}$ & $828.2^{*}$ & $1.1^{*}$ \\
\hline & $\begin{array}{l}\text { Quadratic effect: } \\
\left(10^{6}\right) \mathrm{C}\end{array}$ & $-0.1^{* *}$ & 0.0 \\
\hline \multirow[t]{2}{*}{$Q=$ for shopping } & $\begin{array}{l}\text { Main effect: } \\
\left(10^{3}\right) \mathrm{d}\end{array}$ & $25.0^{* *}$ & $8.4^{* *}$ \\
\hline & $\begin{array}{l}\text { Quadratic effect: } \\
\left(10^{6}\right) \mathrm{e}\end{array}$ & 0.7 & $-0.6^{* *}$ \\
\hline \multirow[t]{2}{*}{$Z=$ for recreation } & $\begin{array}{l}\text { Main effect: } \\
\left(10^{3}\right) \mathrm{f}\end{array}$ & $81.8^{* *}$ & $19.8^{* *}$ \\
\hline & $\begin{array}{l}\text { Quadratic effect: } \\
\left(10^{6}\right) \mathrm{g}\end{array}$ & -4.2 & 0.1 \\
\hline Multiple R & & 0.919 & 0.658 \\
\hline
\end{tabular}

The main effects and quadratic effects are displayed at different exponential levels

Base $\mathrm{N}=506$ census tracts

* Significant at 0.05

** Significant at 0.01

period. Bear in mind that this number is mitigated by the negative quadratic effect, which is especially strong when inflows are squared, offsetting the apparent impact of more workers on more crime. We cannot say how many of these crimes are against businesses or individuals; but we can say that the concentration of workers give certain CTs considerably higher risks of property crime.

Work visitors influence property crime, but add litthe to violent crime, with statistical significance is only at the 0.05 level. Instead, recreation inflows appear to be the main source of violent crime, with every thousand visitors to a $\mathrm{CT}$ adding 20 violent incidents locally. The quadratic 
effect remains, along with the concave downward slope, but only one variable per equation has a negative quadratic coefficient. Swelling numbers of work visitors tend to increase property crimes, but only up to the point when the quadratic effect becomes notable. We recommend caution in teasing apart the impact of different types of visitors due to high correlations among these variables (e.g., $r=0.68$ between shopping and recreation variables.

\section{Conclusion and comments}

The funneling hypothesis is highly sustainable as an explanation of within-city crime concentration. We find strong correlations between visitor variables and crime over 506 CTs. Due to limited access to the transportation survey, we were unable to disaggregate the movements of different age groups or to explore specific time of day or day of week. Nor were we able to separate business from citizen victimizations. Nor could we detail more specific crime types than property or violent crimes. Nor can we say that these findings will generalize to other cities, or to suburban areas, or to newer cities during their growth period. In this city, high correlations among some visitor variables limit our ability to separate their independent contributions with certainty. We cannot say that the four types of visitors would produce the same relative contributions elsewhere, but we remain convinced that visitor effects are strong in this city and merit investigation elsewhere.

Emerging data are beginning to produce alternative measures of daily population flows relevant to crime. For example, the LandScan Global Population Database combines conventional sources with high resolution satellite imagery to estimate 24-h average population for many regions. ${ }^{6}$ Andresen $(2006,2010,2011)$ applied that technology to show that "ambient population" in Vancouver produces different crime rates maps than those based on simple residential population.

Two new reviews consider several ways that emerging technologies help measure crime risks (Bernasco 2014; Van Gelder and Van Daele 2014). Some researchers are beginning to apply smart phone technology (including apps and GPS) to locate crime and study swiftly shifting populations. Japanese criminologists have used GPS data to identify children's activities and vulnerabilities after school and adult neighborhood watch activities (Amemiya et al. 2009).

On a much smaller scale, Rossmo et al. (2012) mapped the space-time paths of a few parolees required to wear location-tracking devices. A novel study in Leeds, UK, relates crime hotspots to rapid shifts in the volume of social media messaging (Malleson and Andresen 2015).

\footnotetext{
${ }^{6}$ Calculated by the Oak Ridge National Laboratory. See also Andresen and Jenion (2008).
}

Others have arranged for youths to describe their spatial movements and fears, using computer screens to simulate their journey home from school (Wiebe et al. 2014). ${ }^{7}$ Both old and new technologies have shed light on how youths allocate time and the consequences for offending or victimization (see review in Hoeben et al. 2014).

We suggest that, on the one hand, emerging technologies offer great promise for detailed measurement of rapidly shifting population for a whole urban system. On the other hand, more conventional surveys might prove more suitable for gathering crimerelevant details about where people go; for what purposes; how much alcohol they drink in different places; their group sizes; and their roles as offender, target, or guardian. Unstructured interviews may also prove useful for determining where offenders search for visitors and how they decide to choose their specific targets. Metropolitan movements shift by hour of day in detailed ways not captured in the current study. These processes depend on local variations in transportation, road networks, and land use patterns. A large national research project is ill-suited to such research, which instead depends on incremental local studies taking into account the local topography and built environment.

From other literature and our own analyses, we conclude that the funneling hypothesis is highly viable, and that the spatio-temporal concentration of crime over urban space is greatly influenced by daily flows of people away from where they live and into other parts of a city.

\section{Authors' contributions}

MF is senior author and responsible for the write-up and planning, while RB was in charge of data analysis and linking data sets, and editing tables and write-up of tables. Both authors read and approved the final manuscript.

\section{Author details}

${ }^{1}$ School of Criminal Justice, Texas State University, San Marcos, TX, USA ${ }^{2}$ School of Criminology, Université de Montréal, Montreal, QC, Canada.

\section{Acknowledgements}

No one else directly participated in this process.

\section{Competing interests}

The authors declare that they have no competing interests.

Received: 13 May 2015 Accepted: 1 October 2015

Published online: 20 October 2015

\section{References}

Amemiya, M., Saito, T., Kikuchi, G., Shimada, T., \& Harada, Y. (2009). Identifying the spatio-temporal characteristics of children's after school activities and adults' neighborhood watch activities using GPS data. Journal of the Japanese Institute of Landscape Architecture, 72, 747-752.

${ }^{7}$ A similar general approach was used in Wang and Taylor (2006), who created a "simulated walk through dangerous alleys." 
Andresen, M. A. (2006). Crime measures and the spatial analysis of criminal activity. British Journal of Criminology, 46, 258-285.

Andresen, M. A. (2010). Diurnal movements and the ambient population: an application to municipal level crime rate calculations. Canadian Journal of Criminology and Criminal Justice, 52, 97-109.

Andresen, M. A. (2011). The ambient population and crime analysis. Professional Geographer, 63, 193-212.

Andresen, M. A., Frank, R., \& Felson, M. (2014). Age and the distance to crime. Criminology and Criminal Justice., 14, 314-333.

Andresen, M. A., \& Jenion, G. W. (2008). Crime prevention and the science of where people are. Criminal Justice Policy Review, 19, 164-180.

Andresen, M. A., \& Malleson, N. (2013). Crime seasonality and its variations across space. Applied Geography, 43, 25-35.

Angel, S. (1968). Discouraging crime through city planning. Working Paper, \#75. Berkeley: Center for Planning and Development Research.

Bernasco, W. (2010). A sentimental journey to crime: effects of residential history on crime location choice. Criminology, 48, 389-416.

Bernasco, W. (2014). Crime journeys: Patterns of offender mobility. Oxford: Oxford University Press.

Bernasco, W., \& Block, R. (2011). Robberies in Chicago: a block-level analysis of the influence of crime generators, crime attractors, and offender anchor points. Journal of Research in Crime and Delinquency, 48, 33-57.

Bernasco, W., \& Luykx, F. (2003). Effects of attractiveness, opportunity and accessibility to burglars on residential burglary rates of urban neighborhoods. Criminology, 41, 981-1001.

Boggs, S. L. (1965). Urban crime patterns. American Sociological Review, 30, 899-908.

Boivin, Rémi. (2013). On the use of crime rates. Canadian Journal of Criminology and Criminal Justice, 55, 263-277.

Bowers, K. (2014). Risky facilities: crime radiators or crime absorbers? A comparison of internal and external levels of theft. Journal of Quantitative Criminology, 30, 389-414. doi:10.1007/s10940-013-9208-z

Brantingham, P. J., \& Brantingham, P. L. (1975). The spatial patterning of burglary. Howard Journal of Criminal Justice, 14, 11-23.

Brantingham, P. L., \& Brantingham, P. J. (1981). Mobility, notoriety, and crime: a study in the crime patterns of urban nodal points. Journal of Environmental Systems, 11, 89-99.

Brantingham, P. L., \& Brantingham, P. J. (1995). Criminality of place: crime generators and crime attractors. European Journal on Criminal Policy and Research, 3, 5-26.

Brantingham, P. L., \& Brantingham, P. J. (1999). Theoretical model of crime hot spot generation. Studies of Crime and Crime Prevention, 8, 7-26.

Burgess, E. W. (1925). Can neighborhood work have a scientific basis? In R. E. Park, E. W. Burgess, \& R. D. McKenzie (Eds.), The city: Suggestions for investigation of human behaviors in the urban environment. Chicago: University of Chicago Press.

Chamlin, M. B., \& Cochran, J. K. (2004). An excursus on the population size crime relationship. Western Criminology Review, 5, 119-130.

Clarke, R. V. (1984). Opportunity-based crime rates: the difficulties of further refinement. British Journal of Criminology, 24, 74-83.

Clarke, R. V., Belanger, M., \& Eastman, J. A. (2007). Where angel fears to tread: A test in the New York City subway of the robbery/density hypothesis. In R V. Clarke (Ed.), Crime prevention studies. Preventing mass transit crime, vol 6. New York: Criminal Justice Press.

Clarke, R. V., \& Eck, J. (2005). Crime analysis for problem solvers in 60 small steps. Washington, D.C.: Office of Community Oriented Policing Services, United States Department of Justice.

Cohen, Lawrence E., \& Felson, Marcus. (1979). Social change and crime rate trends: a routine activity approach. American Sociological Review, 44, 588-608.

Frank, R., Andresen, M. A., \& Brantingham, P. L. (2013). Visualizing the directional bias in property crime incidents for five Canadian municipalities. Canadian Geographer, 57, 31-42.

Franquez, J. J., Hagala, J., Lim, S., \& Bichler, G. (2013). We be drinkin': a study of place management and premise notoriety among risky bars and nightclubs. Western Criminology Review, 14, 34-52.

Groff, E. R. (2011). Exploring "near": Characterizing the spatial extent of drinking place influence on crime. Australian and New Zealand Journal of Criminology, 44, 156-179.

Groff, E. R., \& Lockwood, B. (2014). Criminogenic facilities and crime across street segments in Philadelphia: Uncovering evidence about the spatial extent of facility influence. Journal of Research in Crime and Delinquency, $51,277-314$.
Groff, E. R., \& McEwen, T. (2007). Integrating distance into mobility triangle typologies. Social Science Computer Review, 25, 210-238.

Hakim, S., \& Rengert, G. F. (1981). Crime Spillovers. Thousand Oaks: Sage.

Harries K. D. (1991). Alternative denominators in conventional crime rates. In: P. J. Brantingham and P. L. Brantingham (eds.) Environmental Criminology (pp. 147-165). Prospect Heights, IL: Waveland Press.

Hoeben, E. M., Bernasco, W., Weerman, F. M., Pauwels, L., \& van Halem, S. (2014). The space-time budget method in criminological research. Crime Science, 3,1-15.

Hollis-Peel, M. E., Reynald, D. M., \&Welsh, B. C. (2012). Guardianship and crime: an international comparative study of guardianship in action. Crime, Law and Social Change, 58, 1-14.

Johnson, S. D. (2010). A brief history of the analysis of crime concentration. European Journal of Applied Mathematics., 21, 349-370.

Johnson, S. D. (2014). How do offenders choose where to offend? Perspectives from animal foraging. Legal and Criminological Psychology, 19, $193-210$.

Kurland, J., Johnson, S. D., \& Tilley, N. (2014). Offenses around stadiums: a natural experiment on crime attraction and generation. Journal of Research in Crime and Delinquency, 51, 5-28.

LaRue, E., \& Andresen, M. A. (2015). Spatial patterns of crime in Ottawa: the role of universities. Canadian Journal of Criminology and Criminal Justice, 57(2), $189-214$.

Lemieux, A. M. (2010). Risks of violence in major daily activities: United States, 2003-2005. Doctoral dissertation, School of Criminal Justice, Rutgers University, Newark, NJ.

Lemieux, Andrew M., \& Felson, Marcus. (2012). Risk of violent crime victimization during major daily activities. Violence and Victims, 27(5), 635

Malleson, N., \& Andresen, M. A. (2015). The impact of using social media data in crime rate calculations: shifting hot spots and changing spatial patterns. Cartography and Geographic Information Science, 42(2), 112-121.

McCord, E. S., \& Ratcliffe, J. (2009). Intensity value analysis and the criminogenic effects of land use features on local crime patterns. Crime Patterns and Analysis., 2, 17-30.

Newton, A. (2008). A study of bus route crime risk in urban areas: the changing environs of a bus journey. Built Environment, 34(1), 88-103. (ISSN 02637960).

Pyle, G. F. (1974). The spatial dynamics of crime. Research Paper No. 159. Chicago: University of Chicago Department of Geography

Ratcliffe, J. (2010). Crime mapping: Spatial and temporal challenges, chapter 2. In A. R. Piquero \& D. Weisburd (Eds.), Handbook of quantitative criminology. New York: Springer.

Reynald, D. M. (2009). Guardianship in action: developing a new tool for measurement. Crime Prevention and Community Safety, 11, 1-20.

Reynald, D. M. (2011). Factors associated with the guardianship of places: assessing the relative importance of the spatio-physical and sociodemographic contexts in generating opportunities for capable guardianship. Journal of Research in Crime and Delinquency, 48, 110-142.

Roman, C. G., \& Reid, S. E. (2012). Assessing the relationship between alcohol outlets and domestic violence: routine activities and the neighborhood environment. Violence and Victims, 27, 811-828.

Romley, J. A., Cohen, D. A., Ringel, J. S., \& Sturm, R. (2007). The density of liquor stores and bars in urban neighborhoods in the United States. Journal of Studies on Alcohol and Drugs, 68, 48-55.

Roncek, D. W., \& Bell, R. (1981). Bars, blocks, and crime. Journal of Environmental Systems, 11, 35-47.

Roncek, D. W., \& Fagianni, D. (1985). High schools and crime-a replication. Sociological Quarterly, 26, 491-505.

Roncek, D. W., \& Lobosco, A. (1983). The effect of high schools on crime in their neighborhoods. Social Science Quarterly, 64, 598-613.

Roncek, D. W., \& Maier, P. (1991). Bars, blocks, and crimes revisited: linking the theory of routine activity and opportunity models of predatory victimization. Criminology, 29, 725-753.

Rossmo, D. K., Lu, Y., \& Fang, T. B. (2012). Spatial-temporal crime paths. In M. A. Andresen \& J. B. Kinney (Eds.), Patterns, prevention, and geometry of crime (pp. 16-42). New York: Routledge.

Shaw, C. R., \& McKay, H. D. (1942). Juvenile delinquency in urban areas. Chicago: University of Chicago Press.

Stults, B. J., \& Hasbrouck, M. (2015). The effect of commuting on citylevel crime rates. Journal of Quantitative Criminology,. doi:10.1007/ s10940-015-9251-z. 
Tompson, L., \& Townsley, M. (2010). (Looking) Back to the future: using spacetime patterns to better predict the location of street crime. International Journal of Police Science and Management., 12, 23-40.

Townsley, M., Reid, R., Reynald, R., Rynne, J., \& Hutchins, B. (2014). Risky facilities: Analysis of crime concentration in high-rise buildings. Trends and Issues in Crime and Criminal Justice no. 476. Canberra: Australian Institute of Criminology.

Townsley, M., \& Sidebottom, A. (2010). All offenders are equal, but some are more equal than others: variation in journeys to crime between offenders. Criminology, 48, 897-917.

Uittenbogaard, A. C. (2013). Clusters of urban crime and safety in transport nodes. Doctoral Dissertation. Stockholm: KTH Royal Institute of Technology, School of Architecture and the Build Environment.

Van Gelder, J.-L., \& Van Daele, S. (2014). Innovative data collection methods in criminological research. Crime Science, 3, 1-4.
Wang, K., \& Taylor, R. B. (2006). Simulated walks through dangerous alleys: impacts of features and progress on fear. Journal of Environmental Psychology, 26, 269-283.

Weisburd, D., Groff, E. R., \& Yang, S.-M. (2012). The criminology of place: Street segments and our understanding of the crime problem. Oxford: Oxford University Press.

White, R. C. (1932). The relationship of felonies to environmental factors in Indianapolis. Social Forces, 10, 498-513.

Wiebe, D. J., Richmond, T. S., Poster, J., Guo, W., Allison, P. D., \& Branas, C. C. (2014). Adolescents' fears of violence in transit environments during daily activities. Security Journal, 27, 226-241.

Brantingham, P. L. (eds.) Environmental criminology. Prospect Heights: Waveland Press.

Zhu, L., Gorman, D. M., \& Horel, S. (2004). Alcohol outlet density and violence: a geospatial analysis. Alcohol and Alcoholism, 39, 369-375.

\section{Submit your manuscript to a SpringerOpen ${ }^{\odot}$ journal and benefit from:}

- Convenient online submission

- Rigorous peer review

- Immediate publication on acceptance

- Open access: articles freely available online

- High visibility within the field

- Retaining the copyright to your article

Submit your next manuscript at $>$ springeropen.com 